\title{
Acervo de materiais educativos sobre hanseníase: um dispositivo da memória e das práticas comunicativas *
}

Adriana Kelly-Santos ${ }^{1}$

Simone Souza Monteiro ${ }^{2}$

Ana Paula Goulart Ribeiro ${ }^{3}$

KELLY-SANTOS, A.; MONTEIRO, S.S.; RIBEIRO, A.P.G. Collection of educational materials on Hansen's disease: a tool for memory and communicative practices. Interface -

Comunic., Saude, Educ., v.14, n.32, p.37-51, jan./mar. 2010.

Educational materials form part of the guidelines for Hansen's disease control programs. The aims of the present study were to describe the process of creating a database for 276 educational materials on Hansen's disease that were produced by public and non-governmental institutions between 1972 and 2008, and to analyze the type, target public and objectives. The database was set up electronically and contained a descriptive and thematic analysis and a link to the complete document containing the materials. The materials were targeted at the general public $(75 \%)$, healthcare professionals $(12 \%)$, children and adolescents $(6 \%)$, individuals with Hansen's disease $(3 \%)$, and others $(4 \%)$. Pamphlets $(26 \%)$, leaflets $(24 \%)$ and posters $(23 \%)$ predominated, followed by primers (15\%), flipbooks (3\%) and others ( $9 \%)$. They aimed to increase self-awareness and case detection and to publicize healthcare services. Biomedical discourse using technical-prescriptive language and hierarchical relationships between enunciator and target predominated.

Keywords: Educational materials. Hansen's disease. Communication.
Os materiais educativos integram as diretrizes de Programas de Controle de Hanseníase. Neste trabalho objetivase: descrever o processo de elaboração de um banco de 276 materiais sobre hanseníase produzidos por instituições públicas e não-governamentais, entre 1972-2008; analisar o tipo, o público e os objetivos. O banco foi elaborado numa base eletrônica de dados, contendo a análise descritiva e temática e um link para o documento completo dos materiais. Os materiais destinam-se ao público em geral $(75 \%)$, profissionais de saúde $(12 \%)$, público infanto-juvenil $(6 \%)$, portadores de hanseníase (3\%) e outros (4\%). Predominam panfletos (26\%), folhetos $(24 \%)$, cartazes $(23 \%)$, seguidos de cartilhas (15\%), álbuns seriados (3\%) e outros (9\%). Objetivam aumentar a autossuspeição, detecção de casos e divulgar os serviços de saúde. Predomina o discurso biomédico, a linguagem técnicaprescritiva e as relações hierarquizadas entre enunciador-destinatário.

Palavras-chave: Materiais educativos. Hanseníase. Comunicação. *Elaborado com base em
Kelly-Santos (2009), com
financiamento do CNPq.
${ }^{1}$ Escola Nacional de
Saúde Pública Sérgio
Arouca, Fundação
Oswaldo Cruz. Av. Brasil,
4365, Manguinhos,
Rio de Janeiro, RJ,
Brasil. 21.045-900.
adrianakellyminas@
hotmail.com
2 Laboratório de
Educação, Saúde e
Ambiente do Instituto
Oswaldo Cruz, Fundação
Oswaldo Cruz - Leas/
IOC/Fiocruz.
35cola de Comunicação,
Universidade Federal do
Rio de Janeiro. 


\section{Introdução}

A hanseníase persiste como um grave problema de saúde pública no Brasil que, em 2006, foi o segundo país no mundo com maior número de casos novos (44.436). Além disso, existe um expressivo contingente de menores de 15 anos (3.513) e de casos novos com incapacidades físicas instaladas (2.106). Esses dados indicam a manutenção da cadeia de transmissão da doença e o diagnóstico tardio (World Health Organization, 2007).

Os Programas de Controle de Hanseníase (PCH), nos níveis federal, estadual e municipal, investem na descentralização do diagnóstico, do tratamento e das ações preventivas na rede básica de saúde. Em relação a estas últimas, está previsto o incremento do exame de contatos e das atividades de educação e comunicação, destinadas ao esclarecimento dos sinais e sintomas da doença junto à população (Brasil, 2006). Tal perspectiva, historicamente, recorre ao uso de propagandas publicitárias destinadas à promoção da saúde e ao esclarecimento de doenças, com vistas a fomentar a procura pelos serviços de saúde pública pela população (Araújo, Cardoso, 2007).

No âmbito das práticas comunicativas, dos serviços de saúde, os materiais de divulgação, nos formatos de cartazes, cartilhas, folhetos etc. - convencionalmente denominados de materiais educativos (Monteiro, Vargas, 2006) - fazem parte destas iniciativas e assumem um importante papel na mediação entre profissionais e a população. Na medida em que, no contexto da saúde, estes suportes são utilizados na transmissão de informações e na promoção de mudanças de comportamentos junto à população.

Pesquisas relativas à avaliação de materiais no campo da saúde pública revelam que, mesmo diante do potencial educativo destes recursos, ainda existe uma acentuada tendência, por parte dos profissionais, a utilizá-los de forma instrumental junto à população. Este enfoque está em consonância com as atividades educativas verticais, unilaterais e lineares, marcadas pela fragmentação dos processos comunicativos - que privilegiam o saber do técnico de saúde e excluem o destinatário das etapas de produção (Kelly-Santos, Rosemberg, Monteiro, 2009; Araújo, Cardoso, 2007; Luz, Pimenta, Schall, 2003; Vasconcellos-Silva, Riviera, Rozemberg, 2003).

Devido ao uso corrente de materiais educativos por diferentes atores nas práticas preventivas, considera-se que a sistematização, análise, recuperação, preservação e documentação destes possibilitam compreender e aprofundar as nuanças do processo de produção-circulação-consumo das atividades comunicativas vigentes na hanseníase. Nesta direção, parte-se da premissa que os materiais educativos são dispositivos que legitimam e socializam os saberes e as práticas realizadas na hanseníase, bem como demarcam os lugares de poder de cada um dos sujeitos no processo comunicativo.

Nessa dinâmica, compreende-se que o discurso é produzido pelos diferentes saberes - científico, político, popular, literário etc. - na imanência das práticas cotidianas. O jogo de forças entre os saberes possibilita que um determinado discurso se estabeleça como verdadeiro em relação a outros. A verdade é fruto das relações de poder entre os saberes; portanto, ela é considerada uma construção histórica (Foucault, 2001).

Tendo em vista essas questões, este artigo objetiva descrever o processo de elaboração de um banco de materiais educativos sobre hanseníase; mapear os materiais deste acervo quanto ao formato, objetivo, público, contexto de produção e de uso, às instituições produtoras; bem como analisar as regularidades e raridades que delimitam as relações entre produtores-destinatários no processo comunicativo da hanseníase. 


\section{Procedimentos metodológicos}

\author{
${ }^{4}$ Esta pesquisa foi \\ aprovada pelo Comitê \\ de Ética em Pesquisa \\ da Ensp/Fiocruz \\ (CAAE.0120.0.031.000-
}

07).

${ }^{5}$ Sublinha-se que a inserção da primeira autora no Programa Nacional de Controle de Hanseníase, como assessora técnica nas áreas de comunicação e educação, no período de julho de 2007 a maio de 2008, favoreceu a aplicação das técnicas adotadas e o refinamento e análise dos dados. Além de contribuir para um maior conhecimento e aproximação com a realidade dos programas de hanseníase das diversas regiões do país.

${ }^{6}$ Este encontro foi denominado I Oficina de Comunicação e Educação na Macro-reginal Nordeste, realizada em Recife/PE.

\footnotetext{
${ }^{7}$ Os formatos do acervo foram classificados pela sua estrutura física e citados no texto indicando-se o tipo seguido do número em ordem crescente. Os formatos classificados por folheto apresenta dobras contendo no máximo seis faces; panfleto apresenta frente e verso; cartaz apresenta uma face; cartilha apresenta várias páginas.
}

Trata-se de uma investigação qualitativa ${ }^{4}$, realizada no período de 2003 a 2008, junto a diferentes instituições governamentais e não-governamentais (ONG) que atuam no campo da hanseníase. A diversidade e a dispersão na produção de materiais educativos e o não arquivamento destes recursos exigiram a utilização de variadas estratégias de coleta (Monteiro, Vargas, 2006). Foi adotada a triangulação metodológica (Minayo et al., 2005), que consistiu na combinação de técnicas distintas e complementares, visando à coleta e análise dos materiais educativos sobre hanseníase e a compreensão do contexto de produção dos mesmos. Para tanto, foram entrevistados diferentes atores (gestores e representantes de ONGs), observadas atividades educativas desenvolvidas em um serviço de saúde e coletados materiais educativos durante eventos científicos e visitas institucionais ${ }^{5}$, detalhadas a seguir.

1 Entrevistas semiestruturadas: foram realizadas 12 entrevistas com profissionais que atuam na gestão e na assistência de Programas de Controle de Hanseníase (nos níveis federal, estadual e municipal), situados nas regiões Centro-Oeste, Nordeste e Sudeste, no período de 2004 a 2008. Foram também entrevistados seis representantes de ONG que atuam na produção de materiais educativos - três do Movimento de Reabilitação das Pessoas Atingidas pela Hanseníase (Morhan), um da Federação Internacional de Associações AntiHanseníase (ILEP), um do Instituto Brasileiro de Inovações em Saúde Social (IBISS), um da Fundação Paulista de Combate à Hanseníase. Nesta etapa, foram coletados os materiais produzidos por essas instituições e levantou-se o histórico da produção de materiais e o seu contexto de uso.

2 Observação: foram observadas as atividades de campanhas, salas de espera, os grupos de ajuda mútua e as consultas (médica, da enfermagem e da terapia ocupacional) ambos destinados aos pacientes de hanseníase, atendidos em um posto de saúde da Atenção Básica, situado em uma área endêmica na zona oeste do município do Rio de Janeiro. Também foi observado um treinamento técnico sobre comunicação e educação - para gestores de Programas ${ }^{6}$, promovido pelo Programa Nacional de Controle da Hanseníase (PNCH). Esta etapa, realizada nos anos de 2004, 2007 e 2008, permitiu perceber se os profissionais utilizavam materiais educativos, em que situação o faziam e de que maneira, bem como analisar a interação entre a equipe de saúde e os usuários dos programas.

3 Participação em eventos científicos: a participação nos congressos promovidos pela Sociedade Brasileira de Hansenologia em 2003 e 2007, no Seminário de Hansenologia e Dermatologia organizado pela Secretaria Estadual de Saúde de Tocantins, em 2007, e no Congresso Brasileiro de Saúde Coletiva, ocorrido em 2006, viabilizou a coleta de parte dos materiais educativos que compõem a amostra deste estudo.

A partir das estratégias metodológicas descritas, foi possível reunir um acervo de 276 materiais educativos, constituído de folhetos, cartazes, panfletos, cartilhas, álbum seriado, periódicos, jogos, calendário, cartão-postal, cartão telefônico, imã de geladeira, adesivo, CD-ROM de músicas ${ }^{7}$. Esse acervo foi convertido em um "Banco de materiais educativos sobre hanseníase", com o objetivo de divulgar e fomentar pesquisas sobre os materiais produzidos. $\mathrm{O}$ banco foi construído no formato html e hospedado na plataforma wordpress, por meio de uma ferramenta de geração de conteúdo denominada weblog ou blog, como é popularmente referida, o que permite transportá-lo gratuitamente para diferentes website institucionais. 
Para a sistematização e análise dos materiais, foram adotadas as normas biblioteconômicas de organização de documentos ${ }^{8}$ e a política de indexação utilizada pelo Laboratório de Educação, Ambiente e Saúde do Instituto Oswaldo Cruz - LEAS/IOC (Monteiro, Vargas, 2006), que permitiram atender as especificidades do material do acervo. O processo empregado de classificação e documentação resultou na elaboração de uma tabela que contém os diferentes campos de informação resultante da análise temática e descritiva.

$\mathrm{Na}$ análise temática, foram classificados os tipos dos materiais (formatos) e categorizados o público, os objetivos e os temas. Para estes últimos foi estabelecido um vocabulário controlado, também denominado de descritores, os quais estruturam os índices por assuntos. Essa estrutura favorece as combinações para buscas préestabelecidas e a indexação de novos materiais. Os descritores foram divididos em primários (principais assuntos) e secundários (termos qualificadores dos assuntos principais). $\mathrm{Na}$ análise descritiva, dedicouse à apresentação física do material (autor, editor, estado, região, ano, página, recursos visuais e uma síntese dos conteúdos abordados).

O acervo de materiais educativos estará disponível na Biblioteca da Escola Nacional de Saúde Pública Sérgio Arouca/Fiocruz, que se responsabilizará pela preservação física, pelo arquivamento e pelo recebimento de novos materiais, assegurando a continuidade deste processo de documentação; além de hospedá-lo em sua página principal. O acervo eletrônico também estará on line no Portal da Fiocruz. Esta iniciativa visa democratizar o acesso aos materiais e as suas informações por diferentes grupos sociais (público leigo; portadores de hanseníase, familiares e amigos; profissionais de saúde, educadores, comunicólogos e jornalistas, líderes religiosos, pesquisadores, entre outros).

Com o propósito de analisar as características do banco de materiais quanto às variáveis descritores primários e secundários, Estados e entidades produtoras, objetivos, tipos dos documentos e público, foi elaborado outro banco de dados utilizando-se o programa Statistical Package for Social Science (SPSS) versão 13.0. Estas variáveis foram cruzadas e analisadas tanto do ponto de vista quantitativo quanto qualitativo. A análise qualitativa fundamentou-se no referencial teóricometodológico da Semiologia dos Discursos Sociais - SDS, que se ocupa dos fenômenos sociais como processos de construção de sentidos, considerando os contextos sócio-históricos em que as relações sociais são produzidas (Pinto, 1999; Ribeiro, 1995).

Nesta investigação, busca-se elucidar como, no processo comunicativo da hanseníase, se produzem os sentidos sobre a doença e como, ao mesmo tempo, se produzem as relações de saber e poder entre os enunciadores e os destinatários. Os materiais educativos são tomados como "dispositivos de enunciação", cuja análise pressupõe a ruptura da univocidade e linearidade dos sentidos, e busca entender os modos como os sujeitos concebem discursivamente as relações entre si (Verón, 2004). Os sentidos são constituídos pelo que é dito pelos sujeitos (o enunciado), mas, sobretudo, na maneira como os sujeitos dizem e no modo como constroem os vínculos entre si (enunciação). Neste dispositivo, enunciador e destinatários não são entendidos como sujeitos empíricos, mas são compreendidos como "entidades discursivas". A cada situação discursiva, o produtor real pode construir a imagem de enunciadores e destinatários de maneiras diferentes, bem como estabelecer determinadas relações simbólicas entre eles (Verón, 2004).

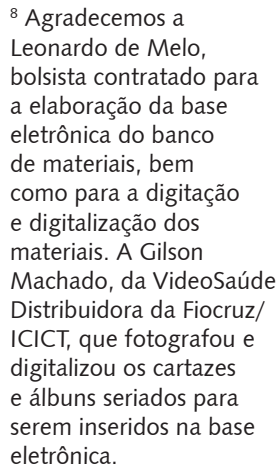




\section{Resultados e discussão}

\section{No rastro da dispersão: mapeamento dos materiais educativos}

\section{Instituições produtoras}

O processo de coleta dos materiais evidenciou que a preservação e a documentação não são desenvolvidas pelos programas de modo sistemático. A produção de materiais tende a ser associada a novas campanhas, nas quais não se avalia a efetividade das estratégias comunicativas adotadas. A avaliação dos materiais educativos, no que diz respeito à análise do produto (conteúdos, diagramação, formatos e sua adequação aos públicos) e do processo (atores envolvidos, estratégias de circulação e dos usos), também é uma prática escassa

${ }^{9}$ As experiências das ONGs IBISS e da Fundação Paulista Contra a Hanseníase na produção e avaliação de materiais, contaram com a participação de profissionais de saúde, portadores de hanseníase e grupos específicos. no campo da hanseníase ${ }^{9}$. Esse fato não é, aliás, uma particularidade desta área, sendo comum a outros Programas de Saúde (Monteiro, Vargas, 2006; Kelly-Santos, Rozemberg, 2005; Luz, Pimenta, Schall, 2003; Rozemberg, 1994).

A criação do acervo de materiais educativos sobre hanseníase representa, assim, um passo importante na criação de uma memória das práticas comunicativas nesta área, em nosso país. Embora esse acervo não represente a totalidade de recursos produzidos, ele reúne grande parte da produção deste campo, no qual estão representados 24 Estados brasileiros e as iniciativas da sociedade civil organizada. Quanto ao período histórico, o acervo abarca os últimos 36 anos (1972-2008). Todavia essa análise é limitada, haja visto que a maioria dos materiais não é datada. A ausência desta informação sugere que os produtores tendem a conceber as ações programáticas independentemente do contexto histórico-social no qual estão inseridas (Kelly-Santos, Rozemberg, 2005). Também revela a pouca ênfase nos estudos de avaliação do uso destes recursos ao longo do tempo.

Verificou-se que, dos 276 materiais, 56\% resultam da parceria entre os Programas de Controle e as ONGs, sendo a maioria desta produção articulada com as ONGs da ILEP, com o Morhan e com o Serviço Franciscano de Solidariedade (Sefras). Os gestores entrevistados relataram que as ONGs são as principais financiadoras das ações de educação e comunicação, viabilizando seu desenvolvimento e continuidade. Embora haja um maior investimento na produção de materiais educativos, foram citadas outras estratégias de mobilização popular, tais como: teatro de fantoches nos serviços de saúde e escolas, uso de pernasde-pau com banda de música, ciranda, capacitação de professores do Ensino Fundamental, palestras com grupos específicos (presidiários e menores infratores) e outras formas de mobilização social (Teixeira, Galiciolli, Rosélia, 2008).

Ainda no que diz respeito às parcerias, constatou-se o papel estratégico do Morhan na definição de políticas governamentais que beneficiem os portadores de hanseníase, bem como as tensões decorrentes das diferentes visões sobre as ações de controle e prevenção propostas pelos representantes dos órgãos governamentais e da sociedade civil organizada. Este dado indica o poder dos movimentos sociais de provocar transformações nas relações institucionais e de redimensionar os lugares dos sujeitos na sociedade (Martín-Barbero, 2003).

Outra parceria identificada refere-se à articulação entre os programas e as empresas privadas, presente em $8 \%$ dos materiais. Apesar das parcerias existentes, nota-se que os gestores exploram pouco o potencial do setor privado como um corresponsável nas ações de mobilização social. Entretanto, constata-se o poder de articulação que o Morhan apresenta junto às instituições privadas, o que indica a sua capilaridade nos diferentes setores da sociedade. Citam-se como exemplos das parceiras do Morhan: Febrafarma, Unimed, Rede Globo, entre outros. 
Considera-se que a mobilização de diversos parceiros aumenta a circulação dos conhecimentos sobre a hanseníase para os diferentes segmentos sociais, de modo a integrá-la no senso comum e contribuir para a modificação da identidade social dos portadores da doença. Há que se considerar também que a participação de diferentes atores e setores sociais no controle da endemia fortalece a prática intersetorial e interinstitucional preconizada pelo Sistema Único de Saúde.

\section{Objetivos e formatos}

No que se refere à definição dos objetivos (explícitos e implícitos) dos materiais, identificou-se que a maioria está relacionada aos formatos e aos públicos para os quais se destinam, além de apresentar mais de um objetivo. Para fins de classificação, optou-se por agrupar os objetivos em cinco eixos, quais sejam: 1 Suspeição e detecção: divulgar informações sobre sinais e sintomas, tratamento e cura; estimular a autossuspeição; mobilizar a procura pelo serviço de saúde e aumentar a detecção de casos novos. 2 Orientação ao profissional de saúde: diagnosticar a doença e os quadros reacionais; realizar exames de contato; promover ações educativas; avaliar as alterações neurológicas que levam às incapacidades físicas; prescrever medicamentos (poliquimioterapira - PQT, a talidomida e corticóides); ensinar ao portador de hanseníase como fazer os exercícios para o autocuidado e para a prevenção de incapacidades físicas; estruturar as atividades desenvolvidas no programa de hanseníase; conhecer a Norma Operacional de Atenção à Saúde (Noas) e atuar na descentralização das ações do programa. 3 Dimensões socioculturais: diminuir o preconceito relacionado com a doença; informar sobre os direitos previdenciários e orientar os portadores de hanseníase sobre condutas destinadas à integração social. 4 Orientação ao portador de hanseníase: usar os medicamentos, fazer exercícios de prevenção de incapacidades físicas e levar os comunicantes para o exame no Posto de Saúde. 5 Divulgação institucional: divulgar o endereço, os projetos e as atividades promovidas pelas instituições; bem como campanhas realizadas pelos serviços de saúde.

Entre os objetivos sistematizados, predominam aqueles orientados à suspeição e à detecção de casos. Essa tendência encontra-se alinhada com a prática campanhista vigente na hanseníase (KellySantos, Rosemberg, Monteiro, 2009). Tal fato torna-se mais evidente ao se correlacionar com a análise dos formatos, cuja maioria dos materiais é de panfletos (26\%), seguida de folhetos (24\%) e de cartazes (23\%). A lógica panfletária focada na disseminação maciça de informação perpetua a vigência de modelos verticais, unilaterais e lineares de comunicação (Araújo, Cardoso, 2007).

$\mathrm{Na}$ tentativa de construir um vínculo mais próximo e direto com a recepção, o produtor lança mão de uma variedade de formatos: cartilhas (15\%); seguidas de álbuns seriados (3\%); adesivos ( $2 \%$ ) e diversos souvenirs (7\%). No conjunto destes materiais, chamam a atenção o cartão-postal, jogos, adesivos, calendários (de bolso e parede), cartões telefônicos, imã calendário, cordéis, a fotonovela e as histórias em quadrinhos. Estes formatos, embora minoritários, destacam-se tanto pelo gênero adotado como pela possibilidade de circulação junto aos diferentes segmentos sociais.

\section{Destinatários e contexto de uso}

Quanto aos destinatários, entre os 276 materiais do acervo, predomina a categoria público em geral (75\%); seguida dos profissionais de saúde (12\%); e do público infanto-juvenil (6\%). Os portadores de hanseníase estão representados em 3\% da amostra. Apenas 1\% dos materiais é destinado ao público escolar. Destaca-se ainda que 3\% dos materiais são dirigidos a mais de um público simultaneamente, portadores de hanseníase, profissional de saúde, população em geral e público escolar.

Constatou-se que o objetivo do material, aliado ao contexto de circulação e de uso, determina a definição do público e dos formatos. As campanhas e as palestras (em escolas, empresas, associação de moradores e igrejas) são atividades privilegiadas para abordar o público em geral, o público escolar e infanto-juvenil. Nessas abordagens, predomina o uso de folhetos, panfletos e cartilhas com conteúdos que visam estimular a autossuspeição e detecção de casos na população. Para os portadores de hanseníase a distribuição de materiais é precária, acontece durante os atendimentos nos serviços de saúde, com vistas a auxiliar na compreensão da doença e na realização dos exercícios de prevenção de incapacidades. No caso dos profissionais de saúde, as cartilhas e os álbuns seriados são usados nos treinamentos técnicos (diagnóstico e tratamento), enquanto os folhetos e cartazes, nas atividades extramuros. 
Na definição dos públicos, avalia-se que a compreensão da situação epidemiológica da doença auxilia no conhecimento de quem são as pessoas e/ou grupos sociais susceptíveis e como eles vivem. A identificação dos elementos - sexo, idade, etnia, hábitos alimentares, acesso a educação, saúde, tipo de ocupação, lazer, religião, rede social, meios de comunicação mais utilizados, preferências - permite especificar os temas, o público e os formatos dos materiais, mas, sobretudo, planejar e definir que estratégia comunicativa é mais efetiva para alcançar determinados grupos.

\section{As relações entre enunciador-destinatário: modos de dizer e mostrar}

\section{A dimensão assimétrica e a prática normalizadora-curativa}

Nas observações de campo no posto de saúde investigado e nas entrevistas com profissionais de saúde e representantes de ONG que atuam na hanseníase, verificou-se que os sujeitos ocupam posições assimétricas no processo comunicativo. O poder de transmitir informaç̧̃es, tratar, educar e oferecer modelos de atitudes é conferido à equipe de saúde. Aos portadores de hanseníase cabe ouvir passivamente as recomendações e colocá-las em prática.

A construção dessa relação acontece por meio do que se denomina prática normalizadora-curativa da saúde. Tais práticas são compreendidas como um conjunto de normas e técnicas (diagnóstico, condutas terapêuticas, busca de contatos, ações educativas, entre outras) delineadas e executadas pelo dispositivo médico-sanitário, com vistas à promoção de medidas preventivas e curativas junto à população. A função social desse dispositivo é normalizar a vida para promover a saúde. Propõe uma série de regras e disciplinas aos sujeitos, cuja finalidade é "endireitar" o que escapa ao funcionamento normal do organismo e dos espaços sociais.

A concepção que orienta esta prática é a da saúde como ausência de doença, como a capacidade do organismo de manter o estado de equilíbrio estável com o meio social (Canguilhem, 2007, 2005). Conforme explicita o texto de um dos materiais, "O micróbio da hanseníase ataca os nervos, o que dificulta os movimentos das mãos, dos pés e dos olhos e causa amortecimentos." (Folheto 41); "As manchas dormentes ou que não coçam [...] Elas têm cura" (Panfleto 54). A cura é vista como a possibilidade de restabelecer as funções normais do organismo, tal como antes do adoecimento. Canguilhen (2005) denomina essa visão como "pedagogia da cura".

Para atingir esse ideal, o saber médico-sanitário lança mão de cuidados universalistas, atuando em prol da "pedagogia da cura". Os enunciados dos materiais evidenciam essa premissa: "O diagnóstico precoce é o melhor remédio" (Panfleto 35); "Todos que conviveram com quem teve a doença devem ser examinados (Folheto 41); "O tratamento é chamado PQT [...] é o mesmo em qualquer lugar do mundo [...] o único que cura hanseníase" (Folheto 14). Ao se constatar essa visão não se quer diminuir a importância dessas atividades, mas ampliar a compreensão do que está instituído como verdadeiro e legítimo no cuidado à saúde.

A prática normalizadora-curativa é recorrente nos materiais educativos e demarca o lugar dos sujeitos no processo comunicativo. As relações entre produtor-destinatário são estabelecidas pelo modo como o enunciador (sujeito que fala no texto) constrói a sua imagem e a do "suposto" destinatário, marcando o lugar de fala de cada um desses atores. A imagem do sujeito da enunciação é construída como aquele que tem o poder de mostrar e fazer o outro crer na informação oferecida; contrapondo-se à imagem do "sujeito falado" (destinatário), que aparece como um sujeito "opaco" (sem rosto, sem voz) e "carente" de capacidade interpretativa.

Do ponto de vista enunciativo, os textos - "Fique atento! [...] Você sabe o que é hanseníase? [...] Fique sabendo - o tratamento é gratuito" (Panfleto 26); "Procure uma unidade de saúde mais próxima de sua casa [...] (Panfleto 49)" - expressam que o sujeito da enunciação detém a autoridade ao narrar o fato - ele é dotado de saber. Isso fica evidente pelo uso do imperativo na construção dos enunciados. Nestas operações, entra em cena a imagem do "enunciador pedagógico" (Verón, 2004) que explica, orienta, prescreve o que o leitor deve aprender e conhecer sobre a hanseníase por meio do uso de perguntas e respostas e frases afirmativas. O conhecimento biomédico é adotado como um recurso pedagógico para criar um código comum sobre os conteúdos a serem transmitidos e assimilados. Conforme explicitado, "A tomada correta de medicamentos previne a evolução da 
doença, garantindo a cura" (Folheto 49). Neste enunciado adota-se a linguagem técnica-prescritiva, relativa ao uso de termos médicos e à indicação de medidas sanitárias de cuidado com a saúde. Essa modalização expressa o modo como o enunciador se faz ouvir e confere credibilidade as suas palavras.

Essa operação se distingue radicalmente nos enunciados "Como posso suspeitar que estou com hanseníase?" (Panfleto 17) e "Onde procurar ajuda? (Panfleto 49)", nos quais o sujeito da enunciação se coloca no lugar do destinatário para se dirigir a ele. Pressupõe, por parte de quem fala, um saber menos totalizante, uma atitude de compartilhar com o interlocutor o acontecimento narrado. Esse deslocamento pode ser meramente retórico, mas ele existe. Indica o uso de estratégias diferentes para buscar a adesão do receptor baseada na construção de certa cumplicidade.

Mediante o exposto, compreende-se que a prática normalizadora-curativa da saúde aliada ao uso de frases afirmativas, imperativas e de perguntas e respostas compõem as regularidades na produção dos discursos da hanseníase. Essas marcas enunciativas determinam os vínculos entre enunciadordestinatário, bem como legitima o saber médico-sanitário como dominante na produção dos significados, valores e representações sobre a doença. A partir destas operações, os materiais educativos atuam como uma mediação modificando a realidade e sendo modificados por ela (Fausto-Neto, 1999, p.16).

Os sentidos e as práticas sobre a hanseníase são gradativamente construídos pela produçãorecepção em cada ato enunciativo. A delimitação do público por categorias representa uma maneira que o produtor real encontrou de transmitir valores e dialogar com os destinatários. Esta caracterização é válida e necessária para instaurar o diálogo entre esses atores, porém ainda predomina a distância nas relações entre os sujeitos do processo comunicativo.

Na categoria "público em geral", o destinatário é representado na maioria das vezes por imagens de partes do corpo humano (tórax, braços, pernas, nádegas, rosto de perfil etc) com lesões características da doença, conforme apresentado no Panfleto 43 (Figura 1). O sujeito aparece sem rosto, sem voz - ele é representado por corpos fragmentos e com lesões. Nessa modalização, o público é tratado como uma "massa atomatizada" (Fausto-Neto, 1995). A noção de "público em geral" é inespecífica e abrangente, própria à concepção universalista de sujeito presente na Saúde Coletiva, a qual ignora marcas de pertencimento dos indivíduos a determinados grupos sociais.

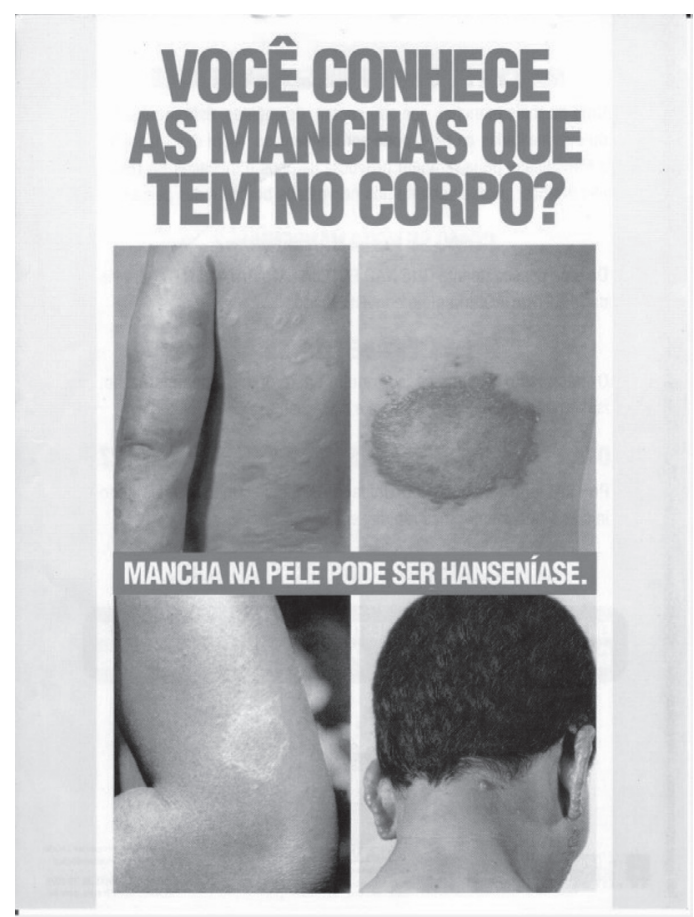

Figura 1. Panfleto 43. 
A identidade e o lugar de cada sujeito na sociedade estão diretamente relacionados com as características socioculturais, intrinsecamente atravessadas por questões referentes ao sexo/gênero, à classe social, etnia, cor/raça, idade. Contudo, os enunciados (textos e imagem) dos materiais ao se referirem a esses marcadores o fazem sem contextualizarem e caracterizarem os indivíduos e as populações susceptíveis. O enunciado "toda e qualquer pessoa pode pegar hanseníase independente de idade, sexo, cor, nacionalidade ou classe social" (Folheto 17) denota esta comunicação genérica, na qual o destinatário é representado sem nenhuma identidade sociocultural. Também desconsidera a localização geográfica e a situação epidemiológica da doença.

Nas categorias "público infanto-juvenil" e "público escolar", o produtor recorre ao uso de ilustrações de crianças e adolescentes e ao gênero história em quadrinhos para estabelecer uma comunicação próxima à realidade desses públicos. Apesar da tentativa bem intencionada e adequada aos destinatários, identificou-se que a ênfase na linguagem técnica-prescritiva privilegia o saber biomédico demarcando quem tem o poder de fala no processo comunicativo.

No caso dos professores, a imagem do destinatário equipara-se à do profissional de saúde, sendo representados como atores ativos e dotados de saber acerca da doença. Já as crianças e os adolescentes ocupam um lugar menos qualificado neste processo, com exceção de alguns materiais que recorrem ao uso de mascotes - o "Previninho" (Folheto 34) e a "Ana Melo" (Cartilha 10) ou de personagens como "Geninho e Leo" (Cartilhas 32,33) e "Masinho" (Cartilha 29) - que constroem a imagem da criança/ adolescente revestida de um certo heroísmo e poder. Nesses casos, esses personagens assumem a função social de educadores na transmissão de informações a seus familiares e amigos.

Na categoria "profissional de saúde", o destinatário, majoritariamente, é representado pelo médico ou pelo enfermeiro, realizando atividades do seu cotidiano (consultas, orientações, palestras) junto aos usuários dos serviços de saúde. A imagem do profissional é investida pelo saber normalizadorcurativo, na medida em que ele é treinado para procurar o agente causal da doença, tomando o corpo como objeto de escrutínio do olhar médico-sanitário: "o exame dermato-neurológico consiste em observar toda a superfície corporal [...], realizar testes de sensibilidade em áreas suspeitas (manchas, placas ou áreas dormentes) e palpar os troncos nervosos mais acometidos na doença" (Folheto 28). O espaço social também é tido como objeto de intervenção sanitária: "Examine todos os comunicantes do paciente e encaminhe para a vacinação com BCG-ID" (Folheto 31). Prioritariamente, o profissional de saúde é representado como aquele que está apto a examinar para diagnosticar e tratar para eliminar, sendo o tratamento medicamentoso a condição para a cura e o alvo dos dispositivos sanitários, como exemplificado no Folheto 09 (Figura 2).

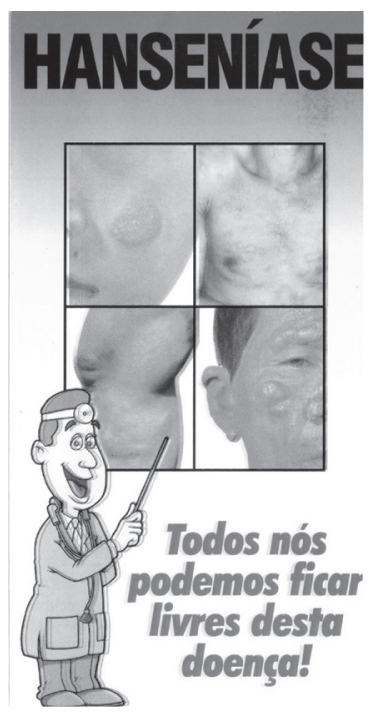

Figura 2. Folheto 9. 
Já o Agente Comunitário de Saúde (ACS) é representado como aquele que vai mediar a relação entre a população e a equipe de saúde. A atuação dos agentes é supervalorizada, por vezes até vista como um ato heróico e missionário:

Abençoado ser ciente de sua cidadania, que se dispõe dia a dia a prestar esclarecimentos e descobrir as mazelas de sua comunidade. [...] Esse ser incansável que desconhece as condições de transportes ou dos perigos dele decorrido, encara sua tarefa como se fosse uma missão divina. É graças a ele que estamos conseguindo ganhar batalhas importantes na área da saúde. (Cartilha 11)

Na categoria "portador de hanseníase", o destinatário é convocado a assumir a responsabilidade na condução do seu tratamento: "a eficácia do tratamento requer atenção e disciplina do paciente e dos familiares" (Panfleto 09). Contudo, ele é representado como um sujeito subserviente ao cuidado normalizador-curativo da equipe de saúde, que deve "ensiná-lo" como agir para restabelecer sua saúde e levar uma vida normal, conforme os enunciados: "O paciente em tratamento pode conviver com a família, no trabalho e na sociedade sem qualquer restrição" (Panfleto 08); "Numa comemoração, o paciente pode até beber um pouco (sem exageros) e comer de tudo, mas nunca deixar de tomar o remédio" (Cartilha 03). Já no texto "O Senhor não precisa se assustar. Nós vamos tratá-lo e tudo vai dar certo" (Cartilha 23), observa-se a busca pela proximidade com o paciente. Apesar do enunciador recorrer a um tom paternal e representar o profissional de saúde como um conselheiro, cuja fala não é autoritária, identifica-se a sua superioridade na relação com o leitor - ele sempre ocupa o lugar daquele que detém o poder e saber no processo comunicativo.

Os enunciados "A cura também depende de você!", associado à imagem de São Francisco (Folheto 65), e "Se você começou e não completou o tratamento volte ao posto de saúde. Sua cura também depende de você" (Folheto 32) convocam à responsabilidade do leitor com os cuidados necessários a sua saúde, além de explicitar a cumplicidade entre enunciador-destinatário nesse processo. Apesar de esses textos forjarem a imagem do enunciador cúmplice-cuidador, o que também se pode evidenciar é o discurso da culpabilização do sujeito. Implicitamente a fala do enunciador aponta tanto para a ideia do necessário envolvimento do sujeito no processo do tratamento, quanto chama a sua atenção pelo descumprimento das normas e dos cuidados médicos provedores de seu bem-estar. $O$ discurso da culpabilização do sujeito por sua doença é recorrente na comunicação de programas de saúde, demonstrando a hegemonia do saber biomédico, em detrimento da valorização dos aspectos subjetivos e dos determinantes socioculturais no processo saúde-doença.

\section{O uso de mediações sociais: espaços de negociação e diálogos entre os sujeitos}

No conjunto de materiais, cabe destacar aqueles que apresentam diferenças no modo como o produtor constrói a relação com o destinatário e a imagem que faz deste. Nessa comunicação, o produtor utiliza elementos que fazem parte do cotidiano das pessoas, de modo a buscar uma interlocução com o destinatário de forma mais direta e personalizada. Um dos recursos refere-se ao uso da mediação "familiaridade" (Martín-Barbero, 2003), cuja estratégia foi a de veicular fotografias do rosto de pessoas sem lesões ou deformidades, de diferentes idades, cor/raça, sexo e segmentos sociais associadas a uma pergunta dirigida ao leitor: "Você diria que eu já tive hanseníase?" (Cartaz 14). Tal mensagem constrói a imagem do leitor representada por pessoas que têm rosto, voz e gestos (sorrisos, olhar atento) e indica que a hanseníase pode afetar qualquer um, sendo esta uma das condições de emergência dos discursos da hanseníase (Rotberg, 1975). Ademais, o que está em jogo nesta abordagem é a possibilidade de restituir a auto-estima do portador de hanseníase e promover um deslocamento no imaginário social, colocando em xeque as imagens terrificantes da lepra - uma doença que mutila e cai pedaços.

Nesta mesma direção, destaca-se a associação entre a "familiaridade" e a "lógica testemunhal" (Verón, 2004) evidenciada nos materiais que trazem fotografias de ex-portadores de hanseníase (homem e mulher), associadas às frases "Eu tive hanseníase. Tratei e estou curada" (Cartão Telefônico 02 e 03). O uso complementar entre a fotografia das pessoas e seus depoimentos atuam como elementos de 
${ }^{10} \mathrm{O}$ artista Ney Matogrosso autorizou a revelação de sua identidade, caso o seu depoimento fosse citado no estudo. reconhecimento e confere um status de verdade à informação veiculada - em especial as relacionadas com o tratamento e a cura, por serem conceitos que dialetizam com o preconceito e o estigma relacionado com a doença.

O modo como estes enunciados (imagens e frases) foram construídos revela uma tendência à relação simétrica entre enunciador-destinatário. O destinatário é representado na imagem de uma pessoa que tem rosto, voz, gestos, afetos e saber, semelhante ao enunciador-produtor. O enunciador compartilha com o destinatário o poder da ação, ao considerá-lo um sujeito ativo dotado de capacidade interpretativa: "Hanseníase temos que saber reconhecer." (Cartão Telefônico 02, 03). Nessa frase, o enunciador busca a cumplicidade com o destinatário.

Entre os materiais, verificou-se ainda o uso da imagem de artistas associada à hanseníase, entre eles: Ney Matogrosso, Elke Maravilha, Nelson Freitas, Patrícia Pilar. Esta estratégia adota a mediação "cultura", com vistas a construir vínculos com o destinatário por meio de sua projeção e identificação com as imagens das celebridades. A exploração da imagem de artistas como produtos-personagens pelos meios de comunicação tem normalmente a função estratégica de provocar a venda e/ou inserção de determinadas mercadorias na vida social (Fausto-Neto, 1991). Na entrevista com o cantor Ney Matogrosso ${ }^{10}$, um dos voluntários do Morhan, observa-se como este elemento de mediação atua na realidade.

\footnotetext{
[...] existe muita curiosidade a meu respeito. Então quando eu estou ligado a um assunto como esse, nós temos assim, às portas da mídia totalmente abertas, eu já fiz muitas campanhas Estaduais [...] realmente nós conseguimos chamar muita atenção para essa doença, que era uma doença complemente ignorada, que sequer publicavam essa palavra em jornal.
}

Outra mediação cultural refere-se ao saber religioso, presente nos folhetos e panfletos que associam as informações sobre a doença às imagens de Santo Antônio, Padre Cícero e São Francisco de Assis. Esses materiais destacam-se devido ao uso das mediações "cotidianidade", "familiaridade" e "cultura" (Mártin-Barbero, 2003), as quais mobilizam o interesse e a curiosidade sobre o tema, bem como potencializam o uso e a interação com estes recursos em diferentes contextos. Um dos entrevistados do Morhan relatou que a utilização do folheto de Pe. Cícero foi uma estratégia que surtiu um ótimo efeito, segundo ele, "as pessoas liam o 'folheto do santinho' e o levavam para casa, colocando-o na sala de visita junto a outras imagens de santos".

Um dos materiais produzidos pelo Sefras, Folheto 16 (Figura 3), utiliza a imagem de São Francisco segurando um leproso, remetendo à memória social da doença. Tal imagem é associada a enunciados sobre as implicações do preconceito e do estigma da lepra, conforme evidenciado nas mensagens " $\mathrm{Na}$ verdade, esta motivação [de atuar na hanseníase] já vem desde o tempo de nosso fundador, São Francisco de Assis, no encontro que teve com o 'leproso' e o levou à superação do seu próprio preconceito em relação à doença" (Panfleto 61) [...] [São Francisco], "tinha um grande amor pelos 'leprosos'. Ajude a vencer o medo e o preconceito da Hanseníase, contribuindo para aumentar o conhecimento dos sinais e sintomas da doença" (Folheto 65). Essa estratégia mobiliza o olhar do leitor e desperta sua compaixão, na medida em que evoca representações ligadas ao abandono social vivido pelos leprosos e ao ideário da assistência "caridosa", "compassiva" e "piedosa" prestada pelos religiosos (Caponi, 2000). 


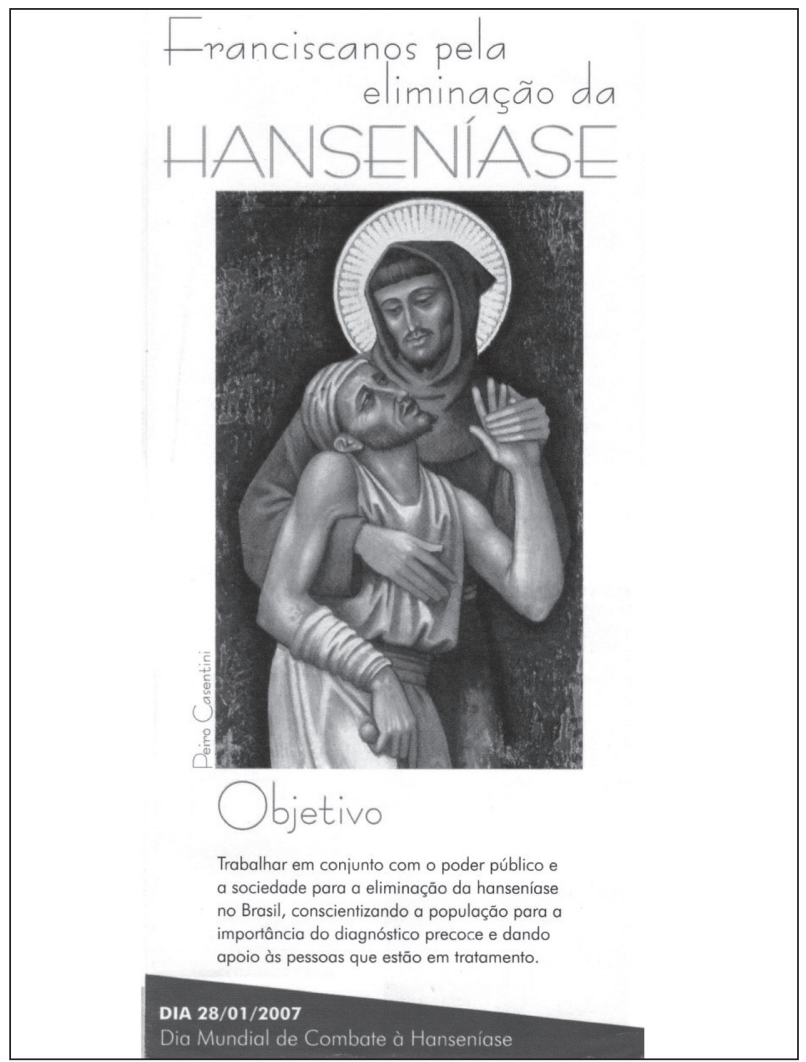

Figura 3. Folheto 16

Nesta modalização, o destinatário é representado como aquele que se compadece com a dor e o sofrimento alheio, ou seja, a ele é atribuído o poder de compartilhar com o enunciador a prática da compaixão piedosa. Estas marcas enunciativas expressam o poder do saber religioso na formação dos conceitos, valores e subjetividade dos sujeitos. Por um lado, a interpenetração entre os saberes religioso e médico opera na construção de um código comum sobre os conteúdos a serem transmitidos ao leitor, deslocando as representações arcaicas e estigmatizantes relacionadas à lepra bíblica. Por outro, ainda é presente no contexto das práticas religiosas o apelo ao discurso culpabilizador no modo como qualificam a doença - como algo impuro, ligada ao pecado e punição divina, cujo efeito é a perpetuação de conceitos ligados ao medo do contágio, à segregação social e às imagens de pessoas mutiladas (Claro, 1995).

\section{Considerações finais}

Os achados deste estudo indicam que, apesar de algumas exceções, há o predomínio de uma comunicação universalista e genérica na divulgação da hanseníase junto ao público. Essa situação indica a precariedade das ações de comunicação e educação vigentes nos programas de controle, além da falta de uma política específica para essa área. A lógica atual concebe atividades comunicativas de maneira pontual, vertical e centralizadas na produção-distribuição de materiais educativos. Esta abordagem fica evidente na produção maciça de panfletos, folhetos e cartazes destinados ao "público em geral", amplamente distribuídos nas campanhas e palestras focadas no aumento da autossuspeição e detecção de casos. 
O pouco investimento em ações continuadas de comunicação-educação e na avaliação das atividades realizadas, aliada à baixa mobilização dos diversos segmentos sociais para o enfrentamento da endemia, representa um dos pontos críticos das ações de vigilância na hanseníase. Mediante este cenário, considera-se que o controle da doença deve ser encarado não de forma isolada e restrita à área de saúde, mas como uma política de governo, o que requer o fortalecimento das intervenções intersetoriais e interinstitucionais.

Essa perspectiva implica em romper com a concepção médico-centralizadora hegemônica na gestão e na assistência da hanseníase, em prol da participação de diferentes grupos sociais nas atividades dos programas, entre elas nas práticas comunicativas. Araújo e Cardoso (2007) discutem que experiências na descentralização das ações de comunicação têm sido minoritárias, mas, quando implementadas, trazem avanços relativos ao empoderamento dos atores sociais, ao surgimento e ampliação de canais de expressão e escuta, à administração e redistribuição de recursos de forma equitativa e contextualizada com as demandas locais. Este processo propicia, em última instância, a participação dos atores sociais nas decisões sobre que "comunicação fazer, para quê, para quem e de que forma" (Araújo, Cardoso, 2007, p.79).

Os resultados de nossa pesquisa indicaram que as iniciativas de estabelecer uma comunicação personalizada e atenta às diversidades socioculturais dos destinatários, em geral, envolveram parceiros variados. Esta produção representa uma minoria dos materiais, os quais conciliam diferentes formatos, gêneros e mediações para criar o vínculo e o reconhecimento com o leitor. No desenvolvimento de estratégias comunicativas é imprescindível levar em conta os dados epidemiológicos, os marcadores socioculturais, bem como os diversos atores como protagonistas de todo o processo.

A valorização da dimensão dialógica da comunicação, que se pauta na construção da alteridade e no interesse por compartilhar (Bakhtin, 2006), é intrínseca às práticas éticas de cuidado. Tal condição é imperiosa para se formarem os vínculos e os afetos entre os sujeitos, por conseguinte, para se pensar a vida, a saúde e o corpo. Ao se levar em conta a comunicação como um espaço dialógico-afetivo e de reconhecimento do sujeito, será possível avançar na passagem da assistência "compassiva" e "piedosa" para uma assistência orientada pela "ética da solidariedade", que prima por "ações que beneficiem os outros, a partir do reconhecimento do outro como um sujeito autônomo capaz de tomar decisões e de fazer escolhas, isto é, aceitar essas ações" (Caponi, 2000, p.45).

Em consonância com essas premissas em nossas investigações, defende-se o uso de materiais educativos como uma mediação na relação entre a equipe de saúde e os usuários dos serviços, como uma forma de potencializar os espaços dialógicos e afetivos, a troca de conhecimentos, valores e significados atribuídos à doença. Ademais, essa dimensão contribui para que a produção de materiais educativos seja participativa, ancorada em necessidades reais, e seja incluída como um componente estratégico no planejamento das ações de controle dos programas e não apenas como um apêndice um paliativo informativo-instrucional.

\section{Colaboradores}

Adriana Kelly Santos realizou as atividades de campo, análise dos dados, estruturação e redação do artigo. Simone Monteiro e Ana Paula Goulart participaram das etapas de estruturação, redação e revisão final do manuscrito. 


\section{Referências}

ARAÚJO, I.S.; CARDOSO, J. Comunicação e saúde. Rio de Janeiro: Fiocruz, 2007.

BAKHTIN, M. [Volochinov]. Marxismo e filosofia da linguagem. São Paulo: Hucitec, 2006

BRASIL. Ministério da Saúde. Plano Nacional de Eliminação da Hanseníase em nível municipal, 2006-2010. Brasília: MS, 2006.

CANGUILHEM, G. O normal e o patológico. Rio de Janeiro: Forense Universitária, 2007.

Escritos sobre a medicina. Rio de Janeiro: Forense Universitária, 2005.

CAPONI, S. Da compaixão à solidariedade: uma genealogia da assistência médica. Rio de Janeiro: Fiocruz, 2000.

CLARO, L.B.L. Hanseníase: representações sociais sobre a doença. Rio de Janeiro: Fiocruz, 1995.

FAUSTO-NETO, A. Comunicação e mídia impressa: estudo sobre aids. São Paulo: Hucitec, 1999.

O impeachment da televisão: como se cassa um presidente. Rio de Janeiro: Diadorim, 1995.

Mortes em derrapagem: os casos Corona e Cazuza no discurso da comunicação de massa. Rio de Janeiro: Rio Fundo, 1991.

FOUCAULT, M. Nietzsche, a genealogia e a história. In: Microfísica do poder. Rio de Janeiro: Edições Graal, 2001. p.15-38.

KELLY-SANTOS, A. A palavra \& as coisas: produção e recepção de materiais educativos sobre hanseníase. 2009. Tese (Doutorado) - Escola Nacional de Saúde Pública Sérgio Arouca, Fundação Oswaldo Cruz, Rio de Janeiro. 2009. (não aparece citado no texto)

KELLY-SANTOS, A.; ROZEMBERG, B. Comunicação por impressos na saúde do trabalhador: a perspectiva das instâncias públicas. Cienc. Saude Colet., v.10, n.4, p.92938, 2005.

KELLY-SANTOS, A.; ROSEMBERG, B.; MONTEIRO, S. Significados e usos de materiais educativos sobre hanseníase: a concepção dos profissionais de saúde pública do município do Rio de Janeiro. Cad. Saude Publica, v.25, n.4, p.857-67, 2009.

LUZ, Z.M.P.; PIMENTA, A.R.; SCHALL, V. Evaluation of informative materiais on leishmaniasis distributed in Brazil: criteria and basis for the production and improvement of health education materials. Cad. Saude Publica, v.19, n.2, p.561-9, 2003.

MARTIN-BARBERO, J. Dos meios às mediações: comunicação, cultura e hegemonia. Rio de Janeiro: Editora UFRJ, 2003.

MINAYO, M.C.S. et al. Métodos, técnicas e relações em triangulação. In: MINAYO, M.C.S.; ASSIS, S.G.; SOUZA, E.R. (Orgs.). Avaliação por triangulação de métodos: abordagem de programas sociais. Rio de Janeiro: Fiocruz, 2005. p.71-104.

MONTEIRO, S.; VARGAS, E.P. (Orgs.). Educação, comunicação e tecnologia: interfaces com o campo da saúde. Rio de Janeiro: Fiocruz, 2006.

PINTO, M.J. Comunicação e discurso: uma introdução à análise de discursos. São Paulo: Hacker Editores, 1999.

RIBEIRO, A.P.G. A história do seu tempo: a imprensa e a produção do sentido histórico. 1995. Dissertação (Mestrado) - Escola de Comunicação, Universidade Federal do Rio de Janeiro, Rio de Janeiro. 1995

ROTBERG, A. Leprosy: a psycho-social-somatic pehenomenon. Int. J. Leprosy, v.43, n.1, p.62, 1975. 
TEIXEIRA, R.; GALICIOLLI, R.; ROSÉLIA, F. Mobilização social: um modelo para ação. Diamantina: Gerência Regional de Saúde de Diamantina, Secretaria de Estado de Saúde de Minas Gerais, 2008.

ROZEMBERG, B. Representação social de eventos somáticos ligados à esquistossomose. Cad. Saude Publica, v.10, n.1, p.30-46, 1994.

VASCONCELLOS-SILVA, P.R.; RIVIERA, F.J.U.; ROZEMBERG, B. Próteses de comunicação e alinhamento comportamental: uma revisão da literatura sobre impressos hospitalares. Rev. Saude Publica, v.37, n.4, p.531-42, 2003.

VÉRON, E. Fragmentos de un tejido. Barcelona: Gedisa, 2004.

WORLD HEALTH ORGANIZATION. Annual subscription. Weekly Epidemiol. Rec., v.25, n.82, p.225-32, 2007.

KELLY-SANTOS, A.; MONTEIRO, S.S.; RIBEIRO, A.P.G. Acervo de materiales educativos sobre enfermedad de Hansen: un dispositivo de la memoria y de las prácticas comunicativas. Interface - Comunic., Saude, Educ., v.14, n.32, p.37-51, jan./mar. 2010.

Los materiales educativos integran las directrices de los Programas de Control de la enfermedad de Hansen. Este trabajo se objetiva: describir el proceso de elaboración de un banco de 276 materiales sobre dicha enfermedad producidos por instituciones públicas y no gobernativas entre 1972 y 2008; analizar el tipo, el público y los objetivos. El banco se elaboró en una base electrónica de datos conteniendo el análisis descriptivo y temático y un link para el documento completo e los materiales. Los materiales se destinan a un público geral (75\%), profesionales de salud (12\%), público infantil y juvenil $(6 \%)$, portadores de la enfermedad de Hansen (3\%) y otros (4\%). Predominan panfletos $(26 \%)$, folletos $(24 \%)$; carteles $(23 \%)$, seguido de cartillas $(15 \%)$, álbumes seriados $(3 \%)$ y otros ( $9 \%$ ). Objetivan aumentar la auto-suspección, detección de casos y divulgar los servicios de salud. Predomina el discurso biomédico, el lenguaje técnico-prescriptivo y las relaciones jerarquizadas entre enunciador y destinatario.

Palabras clave: Materiales educativos. "Hanseniase". Comunicación. 